\title{
Melancolia e Depressão: Um Estudo Psicanalítico ${ }^{12}$
}

\author{
Elzilaine Domingues Mendes ${ }^{3}$ \\ Universidade Federal de Goiás \\ Terezinha de Camargo Viana \\ Universidade de Brasília \\ Olivier Bara \\ Université Lumière Lyon 2
}

\begin{abstract}
RESUMO - O objetivo deste artigo é compreender a melancolia e a depressão e sua relação com a cultura a partir da psicanálise. Para Freud a melancolia é uma psiconeurose narcísica e a depressão um sintoma que pode estar presente em qualquer estrutura psíquica. Ao criar a categoria das psiconeuroses narcísicas Freud se dá conta da insuficiência do modelo neurótico para a compreensão da melancolia. Partindo do pressuposto de que as condições da vida pós-moderna interferem na subjetividade, causando uma mudança na estrutura dos sentimentos, propomos o modelo narcísico-melancólico para a compreensão das patologias contemporâneas. Constatamos que tanto a melancolia quanto a depressão podem ser patologias ou uma posição do sujeito diante das demandas da sociedade do narcisismo e do espetáculo.
\end{abstract}

Palavras-chave: melancolia, depressão, narcisismo, pulsão de morte, psicanálise

\section{Melancholy and Depression: A Psychoanalytic Study}

\begin{abstract}
The objective behind this article is to give an understanding of the cultural relationship of melancholia and depression through a psychoanalysis perspective. From a Freudian standpoint, melancholia is a form of depression and therefore a symptom that can be found in any psychiatric structure. By creating a category for narcissistic psychoneuroses Freud brings to the fore the inefficiency found in the neurotic model for the understanding of melancholia. The authors propose a narcissistic-melancholic model for an understanding into contemporary pathologies. It is hereby noted that both melancholia as well as depression can be seen as pathologies, as much as the stand point of the individual when faced with pressure from a society concerning its narcissist nature.
\end{abstract}

Keywords: melancholia, depression, narcissism, death drive, psychoanalysis

Assim como a melancolia tornou-se uma patologia predominante no século XIX, a depressão tornou-se a forma de expressão do mal-estar nos dias atuais. O sofrimento psíquico manifesta-se atualmente sob a forma de depressão (Birman, 2007; Berlinck, 2008; Edler, 2008; Kehl, 2009; Roudinesco, 2000).

Já não é mais novidade que as transformações sociais, econômicas e culturais alcançadas na contemporaneidade modificaram também as formas de constituição da subjetividade. Essas transformações são consequências da passagem da modernidade para a pós-modernidade, que é caracterizada pela presença da heterogeneidade e da diferença, tendo como características fundamentais a fragmentação, a indeterminação e a desconfiança nos discursos universais. Tudo isso implica numa mudança profunda na estrutura do sentimento (Harvey, 1989). Vivemos numa era marcada pelo questionamento das certezas absolutas, das grandes narrativas, o que por um lado deixa o indivíduo frágil, vulnerável, desbussolado (Lipovetsky,

1 Apoio: CAPES

2 Agradecimentos: Agradecemos a CAPES pela concessão da bolsa que possibilitou esta pesquisa e aos revisores anônimos por suas valiosas sugestões.

3 Endereço para correspondência: Universidade Federal de Goiás, Departamento de Psicologia, Campus Catalão, Rua Doutor Lamartine Pinto de Avelar, 1120, Setor Universitário, Catalão, GO, Brasil. CEP: 75704020, E-mail: elzilained@yahoo.com.br
2004), mas por outro lado, amplia as possibilidades de surgimento de outras interpretações.

Dentre os fatores que contribuíram para essas mudanças ressaltamos as transformações nos laços sociais como a passagem da família extensa para a família nuclear (Birman, 2007), a valorização do individualismo competitivo (Lasch, 1983), da sociedade do espetáculo, com ênfase no mundo das imagens, do consumo exacerbado e do desenvolvimento tecnológico e científico (Debord,1997). A alta valorização do individualismo, do mundo das imagens e do consumo, aliado ao volume excessivo de informações, substitui a troca de experiências, causando o empobrecimento da vida interior e, consequentemente, a dificuldade de simbolização (Ferraz, 2003; Mendes \& Próchno, 2004; Mendes \& Paravidini, 2007). Nesse sentido, segundo Debord (1997), o sujeito passa a valer pelo que aparenta ser e ter. Assim faz-se necessário buscar a melhor performance possível. Nesse contexto, assistimos a uma proliferação de novas psicopatologias como os estados narcisistas, casos limites (borderlines), etc.

Segundo Celes (2009), Green (1983/1988) por meio do conceito de mãe morta, busca discriminar modos do narcisismo que possam dar sustentação à compreensão das formas psicopatológicas contemporâneas. Surge então o modelo melancólico, que reintroduz as questões dos limites. Nesse modelo, o eu é o centro da discussão, uma vez que enfatiza o narcisismo.

As transformações sociais aliadas às transformações na estrutura dos sentimentos nos levam a pensar que o modelo 
neurótico, desenvolvido por Freud para analisar a histeria, é insuficiente para a compreensão das patologias narcísicas. Pensando que o estudo da melancolia em Freud nos permite compreender a constituição subjetiva contemporânea, propomos uma análise destas patologias a partir do modelo narcísico-melancólico, que de acordo com Celes (2009), Moreira (2008), Pinheiro e Verztman (2003) é mais condizente com as características da vida contemporânea. Neste trabalho, seguindo as recomendações de Green (1983/1988), articulamos narcisismo, melancolia e pulsão de morte para compreendermos as patologias contemporâneas.

Birman (2012) faz uma análise das transformações na experiência subjetiva evidenciadas no contraste dos valores entre a modernidade e a contemporaneidade. Para Birman (2012) o mal-estar contemporâneo se inscreve no corpo, na ação e na intensidade, se caracterizando como dor que não pode ser simbolizada. Dentre estas novas formas de subjetivação, a depressão tem se destacado em função de um aumento significativo deste diagnóstico e previsões de que a sociedade futura será predominantemente depressiva (Kehl, 2009).

No entanto, as palavras melancolia e depressão têm sido empregadas corriqueiramente sem uma preocupação com um diagnóstico diferencial. Atualmente, a palavra melancolia tem sido substituída pela palavra depressão, causando, no nosso entendimento, uma grande confusão. Percebemos que na nossa sociedade não encontramos um consenso em relação ao termo depressão, uma vez que alguns autores a associam à melancolia e outros defendem a necessidade de uma distinção entre estas patologias (Moreira, 2002, Kehl, 2009 e Lambotte, 2007).

Nesse contexto, nos interrogamos sobre a origem dessa confusão. O que tem desencadeado o aumento da depressão e o que vem a ser a depressão? Trata-se de um estado ou de uma patologia? Qual a origem da depressão? Melancolia e depressão são sinônimas? Como podemos pensar a melancolia e a depressão a partir da psicanálise?

O objetivo deste artigo é compreender as especificidades da melancolia e da depressão e sua relação com a cultura a partir da psicanálise. Os objetivos específicos são: 1) percorrer a história e a evolução do conceito de melancolia no Ocidente, apontando para o desaparecimento do termo melancolia nos manuais de diagnóstico psiquiátricos e a sua difusão na depressão; 2) analisar os estudos freudianos acerca da melancolia e resgatar a importância desse conceito para a psicanálise; 3 ) ressaltar a importância do diagnóstico diferencial na condução do tratamento psicanalítico; 4) apontar as contribuições de Freud e dos psicanalistas contemporâneos para a compreensão da melancolia e da depressão como sintomas do mal-estar na cultura.

Neste trabalho, faremos um estudo bibliográfico sobre a melancolia e a depressão. Faremos um histórico da evolução do conceito da melancolia no Ocidente. Analisaremos as contribuições freudianas em relação à melancolia. Por fim, para compreendermos as diferenças entre a melancolia e a depressão retomaremos as contribuições dos psicanalistas contemporâneos, particularmente, a posição de Lambotte (2007), que afirma que a melancolia é um tipo de afecção dificilmente classificável e que tende a desaparecer nas escalas de avaliação de humor da psiquiatria contemporânea, que retém apenas o termo depressão e que não corresponde às estruturas psíquicas conservadas pela psicanálise.

\section{História da melancolia}

Desde a Antiguidade aos dias atuais, a melancolia aparece, sem cessar, assumindo diferentes nomes e formas, como tema de estudos médicos ou filosóficos e como inesgotável fonte de inspiração para poetas e artistas. Fala-se da melancolia como sinônima do furor dos alienados, da acedia dos monges, da genialidade na Renascença, da tristeza no Romantismo e da depressão tratada atualmente por psiquiatras e psicólogos (Pringent, 2005).

No século IV a. C. Hipócrates e seu genro Polybe, num trabalho intitulado: A natureza do homem isolam no corpo humano quatro humores: sangue, fleuma, bílis branca e bílis negra. A saúde é definida como o equilíbrio dos quatro humores. A doença provém do domínio de um dos humores sobre os outros. Hipócrates estabelece uma relação entre as características físicas e o comportamento mental (Pringent, 2005).

Ainda no século IV a. C., a noção de melancolia é revolucionada pelo Problema $X X X$ 1. Trata-se de uma monografia sobre a bílis negra, que é atribuída a Aristóteles. Aristóteles define a melancolia como um estado originário da bílis negra que corresponde aos homens de exceção, aos homens que são considerados gênios. Todos os que têm sido homens de exceção, os filósofos, os poetas, os artistas, são manifestamente melancólicos. Eles têm uma propensão a seguir a imaginação que é inseparável da memória. Desta forma, a partir de Aristóteles a melancolia é associada à imaginação (Klibansky, Panofsky \& Saxl, 1964/1989; Prigent, 2005).

Clair (2005) afirma que a partir do século XIV a acedia é associada à melancolia. Os sintomas da acedia e da melancolia se misturam. A acedia e a melancolia são originadas pelas faltas, pelos erros, pelo diabo que semeia a dúvida e a incredulidade. As duas teorias estabelecem uma relação do corpo com a alma.

A Renascença italiana é caracterizada pelo retorno aos escritos de Aristóteles e de Platão. De acordo com Földényi (2012) para Platão o delírio está associado ao poder divino. Durante o sono o escolhido de Deus tem acesso a outro mundo. Ele é capaz de profetizar o futuro.

Antes mesmo do fím do século XVI, há uma desmistificação dos prestígios relacionados à melancolia. Há uma dissociação entre a melancolia e a imaginação e também entre a genialidade e a melancolia. Nos séculos XVII e XVIII ganham relevo os males e as consequências que a melancolia engendra. A melancolia é definida como uma patologia inquietante, ligada à imaginação devendo ser tratada.

No Romantismo o vocabulário da acedia reaparece, os artistas românticos conciliam-se com certas características da melancolia antiga. No plano filosófico e literário, a melancolia é caracterizada como tédio, como falta de interesse pelo mundo externo, dor existencial, paralisia psíquica, tristeza profunda, abatimento, desgosto, etc. 
No século XIX, com a instauração do saber psiquiátrico, a melancolia é associada à doença mental. Para Prigent (2005) com o nascimento da psiquiatria começa-se uma análise dos sintomas da melancolia. Esquirol (1838) e Pinel (1856) a definem como uma mania, uma loucura caracterizada por um delírio parcial com uma tendência triste ou opressiva. Para Esquirol (1805) não somente as paixões são as causas mais comuns da alienação mental, mas ela tem com essa doença e suas variedades, relações de semelhança extraordinária. Segundo Esquirol (1838), a palavra melancolia, consagrada na linguagem vulgar para exprimir o estado de tristeza de qualquer indivíduo, deve ser deixada aos moralistas e aos poetas, que em suas expressões não são obrigados a tanta seriedade quanto os médicos. Esquirol (1838) propõe o termo monomania que designa um estado anormal da sensibilidade física ou moral, com um delírio circunscrito e fixo. Para Esquirol, a monomania é mais frequentemente de origem hereditária, sendo fortificada pelos vícios da educação, e também por causas morais (Clair, 2005).

Esse fato marca o início da substituição, e consequentemente, confusão dos termos melancolia e depressão. De acordo com Berrios (2012), o que facilitou a remodelação da melancolia e a predominância do conceito de doença depressiva foram os estudos de Esquirol (1805, 1838) que ao fazer a distinção entre melancolia e depressão, enfatizou a natureza afetiva primária da doença. Ainda segundo Berrios (2012), a palavra depressão já aparece nos dicionários médicos em 1860.

No século XIX muitos escritores associam melancolia e memória. Freud (1917[1915]/2006) renunciou a aproximar a mania da depressão, preferindo associá-la a um destino subjetivo. Freud estuda as histéricas e compreende que a doença está ligada a um passado distante. Para Freud (1917[1915]/2006) a melancolia é uma psiconeurose narcísica.

\section{O sentido da melancolia na psicanálise}

Freud (1895/1996c), afirma que o afeto que corresponde à melancolia é o luto, o desejo de recuperar algo que foi perdido. Trata-se de uma perda pulsional, da perda da libido. Para Freud, no caso da melancolia é como se houvesse um buraco na esfera psíquica. Esse buraco nos faz pensar em algo que não pôde ser representado.

No texto "Sobre a transitoriedade" Freud (1916[1915]/1996f) tece considerações sobre a dificuldade de um poeta, que ao apreciar a beleza da natureza era invadido por um sentimento de tristeza, por constatar que tudo o que é belo é transitório, uma vez que, está condenado a finitude. Freud conclui que o medo da perda leva o poeta a introjetar o objeto, se identificando com ele. Neste sentido, ele se perde com o objeto tornando-se também transitório.

Freud (1917[1915]/2006) opta por relacionar a melancolia ao luto pelas semelhanças apresentadas nos dois quadros e pelo fato de serem desencadeadas por circunstâncias de vida parecidas. Bom, mas o que seria então a melancolia? O que a diferencia do luto normal?

Para Freud: "O luto é, em geral, a reação à perda de uma pessoa amada, ou à perda de abstrações colocadas em seu lugar, tais como pátria, liberdade, um ideal, etc.” (Freud, 1917[1915]/2006, p. 103). No luto, o indivíduo sofre porque perdeu o seu objeto de amor. O enlutado sofre, porque deseja o objeto de amor, que está ausente. O luto é uma perda real, em função disso, é fácil compreender que a pessoa enlutada não tenha vontade de fazer nada. Na melancolia encontramos as mesmas características do luto profundo, no qual houve a perda real de uma pessoa amada. Porém na elaboração normal do luto, espera-se que a pessoa enlutada retire todo o seu investimento libidinal do objeto perdido. Isso demanda do enlutado um grande dispêndio de tempo e energia. No caso da melancolia é como se houvesse uma negação da realidade exterior e a pessoa se agarrasse ao objeto por meio de uma psicose alucinatória de desejo. A melancolia pode ser uma reação à perda de um objeto amado, mas pode ser também uma reação a uma perda idealizada, na qual o objeto de amor não morreu, mas foi perdido enquanto objeto de amor.

Até aqui, parece que uma das diferenças fundamentais em relação à perda no luto e na melancolia, refere-se ao fato de que no luto a perda pode ser nomeada. No luto, trata-se de uma perda consciente, ao passo que na melancolia, trata-se de uma perda inconsciente, portanto não simbolizada. Interessa-nos investigar o que impede a elaboração da perda na melancolia, uma vez que Freud (1917[1915]/2006) ressalta que existe uma predisposição patológica para o desenvolvimento da melancolia. Freud esclarece: "Entretanto, em algumas pessoas - que por isso suspeitamos portadoras de uma disposição patológica - sob as mesmas circunstâncias de perda, surge a melancolia, em vez do luto" (Freud, 1917[1915]/2006, p. 103).

Como o narcisismo é uma das condições fundamentais para a constituição do eu, partimos do pressuposto de que há uma falha narcísica na constituição do eu, no sujeito melancólico. Sabemos que o eu não é dado à priori. Ele é constituído no decorrer do desenvolvimento. O bebê nasce desprovido de condições básicas para a sobrevivência. É necessário que alguém exerça a função materna, ou seja, propicie os primeiros cuidados, garantindo segurança e conforto ao recém-nascido para que ele possa desenvolver o seu eu.

Nos Três ensaios da teoria da sexualidade (Freud, 1905/1996g), o eu é concebido como lugar pulsional. A princípio, a atividade sexual apoia-se nas funções que servem à preservação da vida, às pulsões de autoconservação. Posteriormente, a necessidade de satisfação sexual dissociase da fome, tornando-se independente. Existem fases do desenvolvimento psicossexual nas quais o prazer percorre as zonas erógenas, localizadas no corpo do indivíduo, desde o nascimento. Cada estágio do desenvolvimento psicossexual fornece uma possibilidade de fixação. A disposição à neurose está relacionada à possibilidade de fixação em uma das fases do desenvolvimento psicossexual.

Os primeiros contatos da mãe com o bebê possibilitam a erogeneização do seu corpo. Assim, o eu se constitui a partir da relação com o outro. Se existem falhas na relação do bebê com o outro, por uma insuficiência ou ineficiência de quem faz a função materna, ou ainda, algum problema no próprio aparelho sensório do bebê, pode haver um desenvolvimento precário da sua personalidade. De acordo com Winnicott (1958/1983), se a mãe é suficientemente 
boa, se ela consegue propiciar ao bebê o suporte necessário às suas necessidades básicas, às vivências relacionadas ao período de dependência absoluta, o bebê consegue passar dessa fase para a dependência relativa, na qual consegue vivenciar as ausências da mãe de uma forma criativa. $\mathrm{O}$ bebê pode encontrar nos objetos que lhe são familiares, que Winnicott denomina transicionais, traços ou marcas da imagem materna, que lhe possibilitam vivenciar a ausência da mãe de forma menos traumática.

Segundo Lazzarini e Viana (2010): “É o outro que concede e possibilita o nascimento do corpo do sujeito e, portanto, a constituição do seu eu" (p. 273). As ausências da mãe são sentidas pela criança como uma falta, uma vez que mostram para a criança que a mãe possui outros interesses além dela, que existe um mundo fora dela. A presença do pai e/ou a ausência da mãe são fundamentais na constituição do sujeito como um ser desejante, um ser da falta, que necessita do outro para se constituir.

No trajeto da libido, das zonas erógenas até a genital há um patamar em que o investimento incide sobre o eu, unificando os objetos parciais do autoerotismo. A fase narcísica tem uma atividade autoerótica. Sua importância consiste no fato de efetivar a constituição do eu pela inauguração de um objeto tomado como total (Sarmento, 2008). Dessa forma, o narcisismo é um estágio normal e indispensável do desenvolvimento do indivíduo. No entanto, muitas pessoas demoram muito tempo nesse estágio, sendo muitas características dessa fase transportadas para as fases posteriores de seu desenvolvimento. Nesse caso, podemos dizer que houve uma fixação no narcisismo, o que pode, posteriormente, predispor o indivíduo a algum tipo de enfermidade.

Para Freud (1914/2004) o narcisismo primário designa um estado precoce no qual a criança investe toda a sua libido em si mesma, ou seja, toma a si mesma, como objeto de amor. $\mathrm{O}$ narcisismo primário é, portanto, necessário à constituição do eu. Já o narcisismo secundário corresponde à retirada do investimento libidinal do mundo exterior e ao redirecionamento dessa libido de volta para o eu. Freud (1914/2004) esclarece: “Assim, esse narcisismo, que se constitui ao chamar de novo para si os investimentos anteriormente depositados nos objetos, pode ser concebido como um narcisismo secundário, superposto a outro, primário" (p. 98). As afecções narcísicas representam um excesso de investimento no eu.

Freud (1917[1915]/2006) relaciona o narcisismo às causas da melancolia. Freud explica que, a princípio, houve uma forte fixação no objeto erótico. No caso da melancolia parece ter havido uma fixação no estágio infantil do narcisismo devido a uma situação sucedida no início do desenvolvimento libidinal e que tenha rompido com algum laço afetivo importante. A escolha objetal do melancólico foi feita sobre base narcisista. Assim, a melancolia é um tipo de escolha objetal que regride ao narcisismo primitivo.

Nas pessoas cujo desenvolvimento libidinal sofreu perturbações, como no caso dos homossexuais e dos perversos, a escolha do objeto de amor não passa pela imagem da mãe, mas pela sua própria imagem. Eles fazem um tipo de escolha de objeto que Freud denomina narcísico, tomam-se a si mesmo como objeto de amor. Freud (1917[1915]/2006) acrescenta: “a predisposição à afecção melancólica (ou uma parte dela) é derivada da predominância da escolha objetal do tipo narcísico" (p. 109). Há uma substituição do amor depositado no objeto por uma identificação com o objeto "a sombra do objeto caiu sobre o Eu” (Freud, 1917[1915]/2006, p. 108).

Freud (1914/2004) explica que uma das condições que faz das pessoas narcísicas as mais atraentes não é apenas de natureza estética, mas a grande atração que elas exercem sobre aqueles que renunciaram ao pleno exercício de seu próprio narcisismo. Dessa forma, numa escolha objetal de tipo narcísico, o objeto de amor será à imagem e semelhança do eu, ou pela transformação do indivíduo num ideal, no qual o objeto de amor será alguém que seja capaz de amar, de elevar a autoestima do eu.

Parece que o mecanismo fundamental para a predisposição à melancolia é a fixação da libido no estágio do narcisismo. Ao se deparar com a perda, real ou ideal, o melancólico regride a um estágio anterior no seu desenvolvimento, no qual houve uma ferida narcísica, ficando paralisado, impossibilitado de realizar o luto, uma vez que há uma retração da libido de volta ao eu. O melancólico se identifica com o objeto perdido.

\section{Melancolia e morte}

Freud (1917[1915]/2006) ao teorizar sobre a melancolia cria a categoria das psiconeuroses narcísicas para explicá-la. A melancolia é uma neurose narcísica, caracterizada por um conflito entre o eu e o supereu, e que pode assumir formas diversificadas de representação clínica. Ao tentar diferenciar a neurose da psicose, Freud (1924[1923]/1996d) pontua:

Podemos provisoriamente presumir que tem de haver também doenças que se baseiam em um conflito entre o ego e o superego. A análise nos dá o direito de supor que a melancolia é um exemplo típico desse grupo, e reservaríamos o nome de 'psiconeuroses narcísicas' para distúrbios desse tipo (pp. 169-170).

De acordo com Lambotte (2007), as neuroses narcísicas são caracterizadas pela perda da estima de si, pela perda de interesse pelo mundo exterior e por uma falha, ou ferida, própria à constituição narcísica do sujeito. Assim, as neuroses seriam caracterizadas por um conflito entre o eu e o id, as psicoses por um conflito entre o eu e a realidade e as neuroses narcísicas por um conflito entre o eu e o supereu.

Ao estudarmos a melancolia nos deparamos com sintomas que a aproxima dos quadros clínicos de psicose. $\mathrm{O}$ predomínio da realidade interna sobre a realidade externa, fazendo com que o indivíduo se isole da sociedade, voltandose para si mesmo, a gravidade dos seus sintomas, a presença de conflitos de ambiguidade e de componentes sádicos nas suas relações e a sua proximidade com a morte, ressaltam os seus perigos e o seu poder destrutivo.

Aqui se impõe uma questão extremamente relevante para compreendermos a estrutura melancólica e as suas características destrutivas. Por que essa proximidade do melancólico com a morte? Como explicar a sua tendência ao masoquismo e ao suicídio? Por que na melancolia o supereu se volta contra o eu de forma tão cruel, mortífera? 
Para Freud (1917[1915]/2006), o eu só pode se condenar à morte a partir do momento em que trata a si mesmo como um objeto, um objeto para o qual o eu dirige toda a sua hostilidade. De acordo com Edler (2008):

"Tal hostilidade se volta ao próprio eu do sujeito numa espécie de confusão entre ele e o objeto. Como resultado dessa ação sádica, temos o ato suicida, a destruição do eu, pela identificação inconsciente com o objeto. $\mathrm{O}$ eu trata a si mesmo como trataria o objeto do seu amor ambivalente" (p. 37).

Quando há a regressão narcísica o objeto se revela mais poderoso do que o eu. No caso em que predomina o sadismo dirigido ao objeto, ele se volta para o eu, que sob a ação do supereu tenta direcioná-lo à autoextinção. O suicídio é uma passagem ao ato, expressa uma dificuldade de simbolização. Em Dostoiévski e o parricídio (1928[1927]/1996b), Freud atribui a melancolia do escritor como derivada dos seus desejos parricidas.

O sentimento de culpa e o desejo de punição presentes na melancolia estão associados à ambivalência de sentimentos vivenciados em relação às figuras parentais, ainda no decorrer do complexo de Édipo. O indivíduo desejou a morte da figura parental, por isso ele se culpa. O melancólico é atacado por seu próprio supereu. $\mathrm{O}$ eu do melancólico é extremamente autocrítico, ele se julga o pior dos humanos e se condena à morte. Humilha-se diante de todos, colocando-se como uma pessoa indigna. Ao delírio de inferioridade, junta a insônia, a inapetência e as pulsões de autodestruição. As autoacusações do melancólico têm um sentido, revelam o seu estado patológico e o predomínio da pulsão de morte. O que revela o caráter patológico desse comportamento do melancólico é a forma que ele faz essas autoacusações, o fato de não se envergonhar e o fato de se sentir satisfeito.

O comportamento do melancólico, as suas autoacusações, a depreciação do sentimento de si, a sua desvalorização e sua expectativa de punição nos levam a afirmar que, o que se perdeu para o melancólico foi o próprio eu. $\mathrm{O}$ eu foi destruído pelo objeto amado/odiado: "a sombra do objeto caiu sobre o Eu" (Freud, 1917[1915]/2006, p. 108). Assim, a melancolia coloca em evidência a pulsão de morte, por meio de um ideal do eu cruel, a ponto de assassinar o sujeito (Freud, 1923/1996a). Hassoun (2002) evoca a crueldade na subjetivação melancólica, revelando que a identificação narcísica do sujeito com o objeto perdido implica na sua tentativa de destruição.

De acordo com Green (1988), o narcisismo é uma teorização deixada em suspenso por Freud. O narcisismo primário não pode ser compreendido como um estado, mas sim como uma estrutura. No início da vida psíquica, o eu é investido de pulsões, sendo em certa medida, capaz de satisfazê-las por si mesmo. Este estado é denominado narcisismo e esta maneira de obter a satisfação, autoerótica. No autoerotismo o corpo toma o lugar do mundo externo. Green aponta que "a característica do narcisismo absoluto é a procura de um nível zero de excitação" (1988, p. 123). Para Green (1988), o desejo é o movimento pelo qual o sujeito é descentrado, no qual a busca pelo objeto de satisfação leva o sujeito a perceber que o seu centro está fora de si, num objeto que lhe falta. Quando o bebê vivencia a sua primeira experiência de falta há a realização alucinatória do desejo.
O bebê estabelece uma relação de causa e efeito entre a realização alucinatória do desejo e a experiência da satisfação. É o narcisismo dos pais em relação aos filhos que possibilita a constituição do eu, uma vez que esse banho narcísico, erogeneizado, faz com que a criança sinta-se desejada. A mãe, ou seu substituto, ao interpretar as necessidades do bebê colabora para a construção da sua imagem corporal. Se há um investimento precário ou excessivo da mãe a constituição da identidade do bebê será prejudicada.

Com o conceito de 'mãe morta' Green (1988), nos possibilita compreender a estrutura narcísica. "A mãe morta é, portanto, ao contrário do que se poderia crer, uma mãe que permanece viva, mas que está, por assim dizer, morta psiquicamente aos olhos da pequena criança de quem ela cuida" (p. 240). No caso em que o bebê se depara com a mãe morta, depois que ele lutou contra a angústia de diversas maneiras, haverá um desinvestimento do objeto materno e a identificação inconsciente com a mãe morta. A libido desviase dos objetos e volta-se para o eu.

Green (1988) ressalta que na melancolia há uma articulação necessária a ser encontrada entre o narcisismo e a pulsão de morte. Na melancolia predomina o narcisismo negativo. $\mathrm{O}$ eu encontra nele mesmo um objeto de amor, por meio do investimento libidinal no eu. O narcisismo permite a ilusão da realização unitária, pela via da identificação imaginária. Desta forma, no narcisismo o eu procura ser amado como seu próprio ideal.

Podemos dizer que existem dois tipos de escolhas amorosas: a escolha objetal, pautada nas primeiras relações objetais, na qual o eu torna-se sujeito de investimento e, a segunda, a escolha narcísica, apoiada na sua própria imagem, na qual o eu torna-se seu próprio objeto de investimento. No caso da melancolia, podemos afirmar que predomina a escolha narcísica, na qual o eu se constitui no próprio investimento amoroso.

Assim, para o desenvolvimento da melancolia enquanto uma patologia fazem-se necessárias algumas condições: a precariedade da relação mãe-bebê, que pode ser compreendida pela presença da 'mãe morta', que dificulta a constituição do eu; a predominância da escolha narcísica, que resulta no investimento na própria imagem como objeto amoroso; a identificação com o objeto de amor perdido e a destruição do objeto amado/odiado por um supereu extremamente rígido. Como vimos, na melancolia a ação da pulsão de morte torna o supereu extremamente forte e cruel a ponto de destruir o eu. Nesses casos, o manejo clínico exige do analista uma atenção especial no que diz respeito à crueldade e violência do melancólico consigo mesmo.

\section{A melancolia e a depressão na psicanálise}

Moreira (2002), ao analisar a evolução dos estudos freudianos sobre a melancolia mostra que desde o início de seus trabalhos Freud distingue a melancolia da depressão. Freud (1895/1996c) afirma que a melancolia é acompanhada de uma anestesia sexual psíquica, na qual o indivíduo não apresenta desejo sexual. Em relação à depressão, ele a aproxima da neurose de angústia. De acordo com Moreira (2002), houve um afastamento da metapsicologia freudiana 
no interior da própria psicanálise. O termo melancolia desapareceu do Manual diagnóstico e estatístico de transtornos mentais, 4a edição, da Associação psiquiátrica americana e da Classificação de transtornos mentais e de comportamento da CID-10, da Organização Mundial de Saúde. Essa dissolução da melancolia na depressão tem sérias consequências teóricas e clínicas, uma vez que faz desaparecer traços distintivos da própria dinâmica psíquica dos pacientes melancólicos, sobretudo, os impulsos destrutivos e o sentimento de culpa. Essa indiferenciação entre melancolia e depressão traz inclusive problemas no estabelecimento da direção do tratamento.

Delouya (2001) pontua que a depressão não consta entre os quadros clínicos clássicos da psicanálise e nunca ocupou um lugar de destaque entre seus temas. Freud fala em estados depressivos. O que significa que a depressão pode estar presente em qualquer estrutura clínica.

Segundo Lambotte (2007), a melancolia é uma patologia narcísica diferente da depressão. A falta de interesse pelo mundo exterior representa um dos sintomas principais tanto da depressão quanto da melancolia. No entanto, na depressão, o sujeito se desinteressa do mundo externo em função de um acontecimento real, traumático, como o luto, dificuldades profissionais, separações, etc. $\mathrm{O}$ desinteresse pelo mundo externo é necessário para a elaboração do acontecimento traumático. Representa um investimento de energia na tentativa de elaboração, de resolução de uma situação traumática, difícil. Além disso, a depressão não está relacionada a uma falha narcísica.

Para Pinheiro (2005) o melancólico não perdeu o objeto, mas perdeu-se no objeto. Quando o depressivo fala do que perdeu, refere-se a uma perda do que ele foi um dia, uma perda de si mesmo. Na depressão também há uma perda, mas uma perda da imagem de si, uma perda que se deu num tempo que não volta mais.

Moreira (2008) ao analisar a diferença entre a melancolia e a depressão retoma o pensamento aristotélico de que a melancolia é inerente aos homens de exceção, faz parte da sua natureza. Neste sentido, na época clássica a melancolia era compreendida não apenas como uma patologia, mas como uma posição subjetiva. Essa análise amplia a concepção da melancolia.

Moreira (2008), Berlinck e Fédida (2000) propõem que a culpa e o conflito são elementos diferenciadores da melancolia. Na depressão o conflito não se dá entre o ego e o superego, daí a ausência de culpa. O conflito se dá entre o ego e o ideal de ego. O vazio ao qual se referem os deprimidos parece ser o vazio de não realizarem os ideais inerentes à cultura do narcisismo, uma cultura que determina um superinvestimento no eu, no consumo, na aparência (Lasch, 1983).

Assim, segundo Moreira (2008), o pensamento ou ruminação presente na melancolia e que acionava todo o processo criativo dos homens de exceção, é substituído pela compulsão, presente na depressão, consumo de drogas, objetos, alimentos, etc. Enquanto no estado de subjetivação melancólico, característico dos homens criativos, filósofos, predominava a simbolização, na depressão temos o vazio, a impossibilidade de lidar com a frustração. Assim, as novas patologias são pobres de simbolização, são caracterizadas pelo trauma, em que o excedente pulsional escoa por meio da ação.

Kehl (2009) afirma que a desesperança no melancólico está relacionada com o fato de o Outro, em sua primeira versão imaginária (materna), não ter conferido ao recémnascido um lugar em seu desejo. Assim, o melancólico ficou preso num tempo morto, no qual o Outro deveria ter comparecido, mas não compareceu. No caso do depressivo, o tempo morto funciona como um refúgio contra as exigências das demandas do Outro. No depressivo, parece que o Outro compareceu em excesso, não deixando espaço para a falta, o que dificulta a capacidade de sonhar.

Fédida (2002) faz uma correlação da depressão com a vivência do tempo e levanta a hipótese de que "a depressão é um afeto cuja característica seria a alteração do tempo, a perda da comunicação intersubjetiva e correlativamente, um extraordinário empobrecimento da subjetividade" (p.11). Fédida afirma que a depressividade faz parte da vida psíquica, é necessária para o desenvolvimento da criatividade. De acordo com Fédida (1999/2003) a depressão é caracterizada por uma falha na simbolização da ausência. Para Kehl (2009) no caso da depressão enquanto uma posição, a criança foi excessivamente atendida por uma mãe extremamente cuidadosa, uma vez que a mãe compareceu antes mesmo que a criança pudesse perceber a falta, o que dificultou a vivência da ausência. Neste caso, a criança abriu mão do seu desejo em função do desejo do Outro. Daí a pobreza imaginária desses pacientes, a incapacidade de sonhar, de acreditar num futuro melhor, de fazer planos.

Para a psicanálise tanto a melancolia quanto a depressão estão relacionadas com a perda. Para Freud a depressão está vinculada a um afeto, sintoma ou estado que envolve tristeza, desgosto, inibição e angústia. Já a melancolia está associada a um estado inconsciente de impossibilidade de elaboração do luto, uma neurose narcísica. A psicanálise se volta para a compreensão da singularidade da vivência da perda e sua significação subjetiva. Neste sentido, o trabalho psicanalítico nos permite resgatar a possibilidade da vivência da perda e possivelmente elaborá-la, o que exige um trabalho cuidadoso de rememoração.

Na atualidade a vida cotidiana é preenchida com inúmeras atividades, que exigem do indivíduo uma organização rígida em relação ao uso do tempo. Uma das características da nossa sociedade é a hiperatividade (Lipovetsky, 2004). Esse excesso de ações impede que o sujeito possa vivenciar as suas experiências de forma tranquila. Não há mais tempo para refletir, relembrar, rememorar, assim como também não há mais espaço para a dor, o sofrimento e a angústia. $\mathrm{O}$ indivíduo é convidado o tempo todo a reagir rapidamente às experiências de perda, o que acaba dificultando e muitas vezes impedindo a elaboração do luto. Os estados de depressão são banalizados, generalizados e medicados, uma vez que alguns médicos, inclusive alguns psiquiatras não têm mais tempo para observar e escutar os pacientes. No entanto, o uso inadequado ou excessivo dos medicamentos contribui para a "desresponsabilização" do sujeito em relação à sua dor. Se o problema da depressão é considerado endógeno, devendo ser medicado, não há nada mais a fazer, a não ser tomar passivamente a medicação e esperar o seu resultado. A medicalização da tristeza ou do luto impede a elaboração 
do trauma, interfere na capacidade criativa e na construção de novas referências.

$\mathrm{Na}$ contemporaneidade, o aumento dos diagnósticos de depressão parece sinalizar um descompasso entre as exigências sociais como a valorização da hiperatividade e do consumo desenfreado e a necessidade de tempo necessária para a elaboração psíquica. Na nossa sociedade nos deparamos com uma cultura que supervaloriza o individualismo, o consumo, o culto ao corpo e o mundo das imagens, o que propicia o surgimento das patologias narcísicas. Assim como a melancolia foi uma forma de expressão do mal-estar no século XIX, a depressão tem sido considerada o mal-estar do século XXI.

No entanto, faz-se necessário diferenciarmos esses quadros clínicos, uma vez que a melancolia consiste numa patologia na qual nos deparamos com uma destruição do eu. Nossos profissionais de saúde devem estar atentos aos aspectos clínicos analisados por Freud em relação à melancolia, devem tomar cuidado ao diagnosticar um paciente, uma vez que o diagnóstico é o ponto de partida na condução do processo terapêutico.

Em trabalho anterior (Mendes, 2013), constatamos que a melancolia é uma patologia narcísica, mas também um sintoma de uma sociedade que supervaloriza o individualismo. Acreditamos que as condições para a emergência das patologias narcísicas, que por sinal tem aumentado na contemporaneidade, já estavam postas no início do século XIX, com a instauração dos princípios que desencadearam a Revolução Francesa, e consequentemente, com as mudanças na organização dos laços sociais.

Constatamos que na melancolia predomina um conflito entre o eu e o supereu, enquanto na depressão o conflito se dá entre o eu e o ideal do eu. A melancolia pode ser uma patologia narcísica, caracterizada por uma falha na constituição do eu, na qual predominam os impulsos destrutivos, podendo levar à destruição do eu, mas pode também ser uma posição subjetiva, caracterizada pela capacidade de simbolização. No entanto, a depressão também pode ser uma patologia ou uma posição subjetiva acionada pela resistência às altas demandas da sociedade que supervaloriza a produção, o consumo e o espetáculo. Nesse caso, o depressivo se vê impossibilitado de atender às exigências sociais. $\mathrm{O}$ excesso de atividades e exigências da condição de vida pós-moderna diminui a troca de experiências e aumenta a pobreza interior, trazendo como consequências um sentimento de vazio, o que dificulta o processo de simbolização.

\section{Considerações Finais}

Freud (1917[1915]/2006) ao teorizar sobre a melancolia questiona a famosa sentença de Esquirol $(1905,1938)$, que abandona o termo melancolia aos poetas e filósofos, empregando no seu lugar, o termo monomania. Freud retoma o termo melancolia e a define como uma patologia, uma neurose narcísica.

Podemos inferir que ao criar a categoria das psiconeuroses narcísicas para explicar a melancolia, Freud se dá conta da insuficiência do modelo neurótico na análise dos quadros melancólicos e dá os primeiros passos para a compreensão das patologias contemporâneas, denominadas psicopatologias do vazio, narcísicas. Constatamos que no caso das patologias narcísicas o modelo narcísico-melancólico, desenvolvido por Green, se mostra mais adequado para a compreensão das patologias contemporâneas. No entanto, não devemos abandonar nem o modelo neurótico, nem o paranoico na análise dos processos de subjetivação, uma vez que um modelo de entendimento do psiquismo não exclui o outro.

Concluímos que a psicanálise se constitui como um discurso importante na compreensão dos problemas sociais e culturais da sociedade contemporânea. Quando Freud criou a psicanálise prevaleciam valores fundamentados em grandes ideais e que privilegiavam a coletividade. A figura paterna ocupava um lugar central, o que de certa forma regulava o desejo e dava um mínimo de conforto ao indivíduo. Já na nossa condição de vida pós-moderna constatamos a crise da paternidade, o que facilita a proliferação da cultura do narcisismo, com um investimento no individualismo, na competitividade e no consumo. Na contemporaneidade constatamos uma precariedade na constituição do superego. Não existem mais leis capazes de frearem o desejo do ser humano. Nossa sociedade padece da falta de limites que culmina no aumento da violência não apenas nas classes menos abastadas, mas nas famílias ditas 'normais'.

Nosso trabalho não tem a pretensão de esgotar o estudo da melancolia e da depressão, muito menos das psicopatologias contemporâneas. Considerando que as transformações sociais, econômicas e culturais interferem na evolução da subjetividade, causando uma mudança na estrutura dos sentimentos, sugerimos aos psicanalistas contemporâneos um estudo mais aprofundado das patologias narcísicas, que têm se colocado como um desafio para a psicanálise contemporânea, a partir do modelo narcísico-melancólico.

Neste trabalho, concluímos que a depressão pode ser um estado, que pode aparecer numa estrutura neurótica ou psicótica, mas pode também ser uma posição assumida pelo sujeito diante das demandas do Outro. A depressão pode ser uma posição subjetiva do sujeito contemporâneo diante das demandas culturais que supervalorizam o individualismo e a cultura do espetáculo. Diante de tais exigências, o depressivo fica paralisado, distanciado em relação ao seu desejo, o que pode ser interpretado como uma resistência a essas demandas sociais. Neste caso, podemos articular a posição depressiva como fruto de uma sociedade na qual impera a exigência do gozo, uma sociedade que não tolera a falta, a dor, o sofrimento. O depressivo se vê imobilizado diante das possibilidades que as escolhas o envolvem. Ele não sabe lidar com as perdas, fica paralisado. Sendo assim, a depressão pode se constituir como uma posição do sujeito ou ainda como uma dentre outras patologias da condição de vida pós-moderna.

As perdas, das ilusões, dos desejos ou a morte de um ente querido, trazem além da dor, a certeza da finitude. Ao entrar em contato com qualquer tipo de perda, o indivíduo é confrontado com a situação de desamparo. A perda coloca o indivíduo diante da castração, diante de um limite, de uma impossibilidade da qual ele não pode ir adiante. Para a psicanálise o desenvolvimento psíquico se dá por meio da vivência das frustrações e elaborações das perdas. A subjetividade na atualidade, atormentada pelo excesso do 
consumo e pelo acúmulo de objetos, impede que o sujeito vivencie a possibilidade de perder. Nesse caso, o sujeito se defronta com a impossibilidade de perceber que a perda traz consigo a possibilidade de acesso ao universo simbólico. Nesse sentido, a psicanálise ao valorizar a escuta e o método interpretativo abre a possibilidade de restituir ao sujeito deprimido a sua capacidade depressiva e, por conseguinte, a sua criatividade psíquica.

\section{Referências}

Berlinck, L. C. (2008). Melancolia: rastros de dor e de perda. São Paulo: Humanitas: Associação de Acompanhamento Terapêutico.

Berrios, G. E. (2012). Melancolia e depressão durante o século XIX: uma história conceitual (L. A. Ávila, Trad.). Revista Latinoamericana de Psicopatologia Fundamental, 5(3), http:// dx.doi.org/10.1590/S1415-47142012000300011.

Birman, J. (2012). O sujeito na contemporaneidade: espaço, dor e desalento na atualidade. Rio de Janeiro: Civilização Brasileira.

Birman, J. (2007). Laços e desenlaces na contemporaneidade. Jornal de Psicanálise. 40(72), 47-62.

Celes, L. A. M. (2009). Clínica Psicanalítica: Aproximações Histórico-Conceituais e Perspectivas Futuras. Psicologia: Teoria e Pesquisa, 26(1), 65-80.

Clair, J. (2005). Mélancolie: génie et folie en Occident: en hommage à Raymond Klibansky. Paris: Gallimard.

Debord, G. (1997). A sociedade do espetáculo (E. dos S. Abreu, Trad.). Rio de Janeiro: Contraponto.

Delouya, D. (2001). Depressão. São Paulo: Casa do Psicólogo.

Edler, S. (2008). Luto e melancolia: à sombra do espetáculo. Rio de Janeiro: Civilização Brasileira.

Esquirol, J. E. D. (1805). Des passions considérées comme causes, symptômes et moyens curatifs de l'aliénation mentale. Retrieved from http://www2.biusante.parisdescartes.fr/livanc/ ?cote $=$ TPAR $1805 \times 574 \&$ do $=$ pdf.

Esquirol, J. E. D. (1838). Des maladies mentales consideréessous les rapports médical, hygiénique et médico-legal. Paris: J. B. Baillière. Tome II. Gallica.bnf.fr/Bibliothèque Nationale de France.

Fédida, P. (2002). Dos benefícios da depressão: elogio da psicoterapia (M. Gambini, Trad.). São Paulo: Escuta.

Ferraz, F. C. (2003). A loucura suprimida: normopatia, pósmodernidade e instituições psicanalíticas. In L. B. Fucks, \& F. C. Ferraz (Eds.), Desafios para a psicanálise contemporânea (pp. 79-90). São Paulo: Escuta.

Földényi, L. F. (2012). Mélancolie: essai sur l'âme occidentale (N. Zaremba-Huzsvai, \& C. Zaremba, Trads). Berlin: Actes sud.

Freud, S. (1996a). Dois verbetes de enciclopédia. In J. Salomão, (Trans.), Edição Standard das Obras Psicológicas Completas de Sigmund Freud. (Vol. XVIII, pp. 249-274). Rio de Janeiro: Imago. (Trabalho original publicado em 1923)

Freud, S. (1996b). Dostoievski e o parricídio. In Edição Standard das Obras Psicológicas Completas de Sigmund Freud. (Vol. XXI, pp. 181-200). Rio de Janeiro: Imago. (Trabalho original publicado em 1928[1927])
Freud, S. (1996c). Manuscrito G. Melancolia. In Edição Standard das Obras Psicológicas Completas de Sigmund Freud. (Vol. I, pp. 246-253). Rio de Janeiro: Imago. (Trabalho original publicado em 1895)

Freud, S. (1996d). Neurose e psicose. In Edição Standard das Obras Psicológicas Completas de Sigmund Freud. (Vol. V, pp. 163-171). Rio de Janeiro: Imago. (Trabalho original publicado em 1924[1923])

Freud, S. (1996e). Psicologia do grupo e análise do ego. In Edição Standard das Obras Psicológicas Completas de Sigmund Freud. (Vol. XIII, pp. 79-154). Rio de Janeiro: Imago. (Trabalho original publicado em 1921)

Freud, S. (1996f). Sobre a transitoriedade. In Edição Standard das Obras Psicológicas Completas de Sigmund Freud. (Vol. XIV, pp. 315- 319). Rio de Janeiro: Imago. (Trabalho original publicado em 1916a[1915])

Freud, S. (1996g). Três ensaios sobre a teoria da sexualidade. In Edição Standard das Obras Psicológicas Completas de Sigmund Freud. (Vol. VII, pp. 119-231). Rio de Janeiro: Imago. (Trabalho original publicado em 1905)

Freud, S. (2004). À guisa de introdução ao narcisismo. In Escritos sobre a psicologia do inconsciente. Obras Psicológicas de Sigmund Freud. (Vol.1, pp. 95-131). Rio de Janeiro: Imago. (Trabalho original publicado em 1914)

Freud, S. (2006). Luto e Melancolia. In Escritos sobre a psicologia do inconsciente. Obras Psicológicas de Sigmund Freud. (Vol. 2, pp. 99-122). Rio de Janeiro: Imago. (Trabalho original publicado em 1917[1915])

Green, A. (1988). Narcisismo de vida, narcisismo de morte (C. Beliner, Trad.). São Paulo: Escuta.

Hanns, L. A. (1996). Dicionário comentado do alemão de Freud. Rio de Janeiro: Imago.

Harvey, D. (1992). Condição pós-moderna: uma pesquisa sobre as origens da mudança cultural (A. U. Sobral, \& M. S. Gonçalves, Trads.). São Paulo: Loyola.

Hassoun, J. (2002). A crueldade melancólica. (R. Aguiar, Trad.). Rio de Janeiro: Civilização Brasileira.

Hersant, Y. (2005). Mélancolie rouge. Em Clair, J. (Ed.). Mélancolie: génie et folie en Occident. : en hommage á Raymond Klibansky, 1905-2005: [exposition] Galeries nationales du Grand Palais, Paris, 10 octobre 2005-16 janvier 2006 ; Neue Nationalgalerie, Berlin, 17 février-7mai 2006/[organisée par la Réunion des musées nationaux et les Staatliche Museen zu Berlin]; [commissariat général Jean Clair. Gallimard].

Kehl, M. R. (2009). O tempo e o cão: a atualidade das depressões. São Paulo: Boitempo.

Klibansky, R., Panofsky, E., \& Saxl, F. (1989). Saturne et la melancolie. Etudes historiques et philosophiques: nature, religion, médecine et art (F. Durand-Bogaert \& L. Évard. Trads.). Paris: Gallimard. (Trabalho original publicado em 1964)

Lambotte, M.-C. (2007). La mélancolie. Études cliniques. Paris: Economica Anthropos.

Laplanche, J. \& Pontalis J.-B. (1988). Vocabulário de Psicanálise (P. Tamem, Trad.). São Paulo: Martins Fontes Editora.

Lasch, C. (1983). A Cultura do Narcisismo: A Vida Americana numa Era de Esperanças em Declínio (E. Pavaneli, Trad.). Rio de Janeiro: Imago. 
Lazzarini, E., \& Viana, T. C. (2010). Ressonâncias do narcisismo na clínica psicanalítica contemporânea. Análise Psicológica. 2(XXVIII), 269-280.

Lipovetsky, G. \& Charles, S. (2004). Os tempos hipermodernos. São Paulo: Bacarolla.

Mendes, E. D., \& Próchno, C. C. S. C. (2004). Corpo e novas formas de subjetividade. Psychê. VIII(14), 147-156.

Mendes, E. D. \& Paravidini, J. L. L. (2007). Os significantes da escuta psicanalítica na clínica contemporânea. Psychê. XI(20), 96-116.

Mendes, E. D. (2013). Da perda das ilusões à melancolia: um estudo psicanalítico em Balzac (Unpublished doctoral dissertation). Universidade de Brasília, Brasília.

Moreira, A. C. G. (2002). Clínica da melancolia. São Paulo: Escuta/ Edufpa.

Moreira, J. O. (2008). Da melancolia dos dias cinzentos à depressão das noites sem fim. Arquivos Brasileiros de Psicologia, 60, 32-39.
Pinel, C. (1856). De la monomanie, considérée sous le rapport psychologique, médical et légal, par M. le Dr. Cir Pinel neveu. Paris: Labé. Gallica.bnf.fr/Bibliothèque Nationale de France.

Pinheiro, T. (2005). Depressão na contemporaneidade. Pulsional: Revista de Psicanálise. Clínica Social, XVIII(182), 101-109.

Pinheiro, T., \& Verztman, J. S. (2003). As novas subjetividades, a melancolia e as doenças auto-imunes. In T. Pinheiro (Ed.), Psicanálise e formas de subjetivação contemporâneas. (pp. 77-104). Rio de Janeiro: Contra Capa.

Prigent, H. (2005). Mélancolie: les métamorphoses de la dépression. Paris: Gallimard.

Roudinesco, E. (2000). Por que a psicanálise? (V. Ribeiro, Trad.). Rio de Janeiro: Zahar.

Sarmento, M. M. (2008). Construções entre narcisismo e perda na depressão (Unpublished master's thesis). Universidade de Brasília, Brasília.

Winnicott, D. (1983). O ambiente e os processos de maturação. Porto Alegre: Artmed. (Trabalho original publicado em 1958) 